\title{
Neuroborreliose Tardia num Estudante em Programa Erasmus
}

\section{Late Neuroborreliosis in an Erasmus Programme Student}

\author{
Fábio Videira SANTOS $\rrbracket^{1}$, Ana CIPRIANO ${ }^{1}$, Miguel Araújo ABREU ${ }^{1}$, Carlos ANDRADE², Rui SARMENTO-CASTRO ${ }^{1}$ \\ Acta Med Port 2018 Sep;31(9):509-511 - https://doi.org/10.20344/amp.9938
}

RESUMO

A doença de Lyme é uma zoonose endémica nos Estados Unidos da América (EUA), na Ásia e no continente europeu, nomeadamente nos países do centro da Europa. Trata-se de uma doença multissistémica, com manifestações cutâneas, articulares, neurológicas e cardíacas, que variam de acordo com a fase da doença. Apresentamos o caso de uma neuroborreliose tardia num jovem estudante belga a residir temporariamente no Porto. Discutimos a importância da suspeita epidemiológica, a investigação etiológica, os critérios de diagnóstico e o tratamento mais adequado.

Palavras-chave: Europa; Neuroborreliose de Lyme; Viagem

\section{ABSTRACT}

Lyme disease is an endemic zoonosis, the most prevalent tick-transmitted infection in temperate areas of Europe, North America and Asia. It is a multisystemic disease with cutaneous, musculoskeletal, neurologic and cardiac manifestations, according to the stage of the disease. We describe a case of late neuroborreliosis in an Erasmus programme student living in Porto. We discuss the importance of the epidemiological suspicion, the clinical approach, the diagnostic criteria and the most adequate treatment.

Keywords: Europe; Lyme Neuroborreliosis; Travel

\section{INTRODUÇÃO}

A doença de Lyme é uma zoonose endémica com maior prevalência em regiões com clima temperado, nomeadamente nos Estados Unidos da América (EUA), na Ásia e na Europa, particularmente nos países escandinavos e centrais (Áustria, Eslovénia e Alemanha), ${ }^{1}$ provocada por espiroquetas do complexo Borrelia burgdorferi sensu lato. $\mathrm{Na}$ Europa, as espécies mais comuns são a Borrelia afzelii e a Borrelia garinii, transmitidas por picada do artrópode Ixodes ricinus complex. ${ }^{2}$

É uma patologia multissistémica, com manifestações cutâneas, articulares, neurológicas e cardíacas, que variam de acordo com a fase da doença. ${ }^{3} \mathrm{O}$ envolvimento agudo do sistema nervoso ocorre em $10 \%-15 \%$ dos indivíduos, sendo mais comum a meningorradiculite (síndrome de Bannwarth), seguida da meningite linfocítica ${ }^{4}$

A neuroborreliose tardia ou crónica implica mais de seis meses de evolução, ${ }^{1,5,6}$ estando descrita em menos de $2 \%$ dos casos, geralmente sob forma de meningite ou encefalomielite crónicas. ${ }^{1}$ O seu diagnóstico baseia-se na clínica, características do líquor e serologias. Recomenda-se uma investigação em duas etapas: teste de rastreio com ensaio de imunoabsorção enzimática (enzyme-linked immunosorbent assay - ELISA) e Western-blot confirmatório. ${ }^{1}$ A pleocitose no líquor e a evidência de produção intratecal de anticorpos para a Borrelia spp são mandatórios na definição do diagnóstico. ${ }^{1,2}$

\section{CASO CLÍNICO}

Apresentamos o caso de um homem de 21 anos, bel- ga, estudante ao abrigo do Programa Erasmus, a residir no Porto desde setembro de 2016, num apartamento com boas condições. Não tinha contacto com pessoas doentes e tinha a vacinação actualizada.

Recorreu ao Serviço de Urgência (SU) do Centro Hospitalar do Porto (CHP) em janeiro de 2017 por quadro com quatro dias de evolução de cefaleias tipo tensional de predomínio frontal, fono e fotofobia, dificuldade na construção de frases e nomeação de objectos, e vómitos alimentares frequentes. Sem febre documentada.

Negava antecedentes patológicos, medicação crónica, consumo de substâncias ilícitas ou comportamentos de risco. Referia que, duas semanas após viagem à Eslovénia, em junho de 2016, onde caminhou ao ar livre, teve durante uma semana vários episódios de cefaleias holocranianas intensas, que o acordavam durante a noite, sem outros sintomas acompanhantes. Foi observado por um neurologista no seu país, com estudo inconclusivo (tomografia computorizada crânio-encefálica - TC-CE normal) e resolução gradual espontânea. Persistia desde então astenia, impossibilitando a actividade física habitual.

Objectivamente salientava-se apirexia e rigidez terminal da nuca. Analiticamente sem aumento dos parâmetros inflamatórios, realizou TC-CE, sem alterações. A punção lombar (PL) revelou pleocitose com predomínio de mononucleares e ligeira proteinorráquia. Admitido na enfermaria sob ceftriaxona e aciclovir, por suspeita inicial de meningoencefalite linfocítica aguda de etiologia vírica. Foi repetida PL às 48 horas com diminuição da pleocitose (Tabela

1. Serviço de Doenças Infecciosas. Centro Hospitalar do Porto, EPE. Porto. Portugal.

2. Serviço de Neurologia. Centro Hospitalar do Porto, EPE, Porto. Portugal.

$\triangle$ Autor correspondente: Fábio Videira Santos. fabiovideirasantos@gmail.com

Recebido: 13 de novembro de 2017 - Aceite: 04 de abril de 2018 | Copyright @ Ordem dos Médicos 2018 
Tabela 1 - Características citológicas e bioquímicas das punções lombares efectuadas

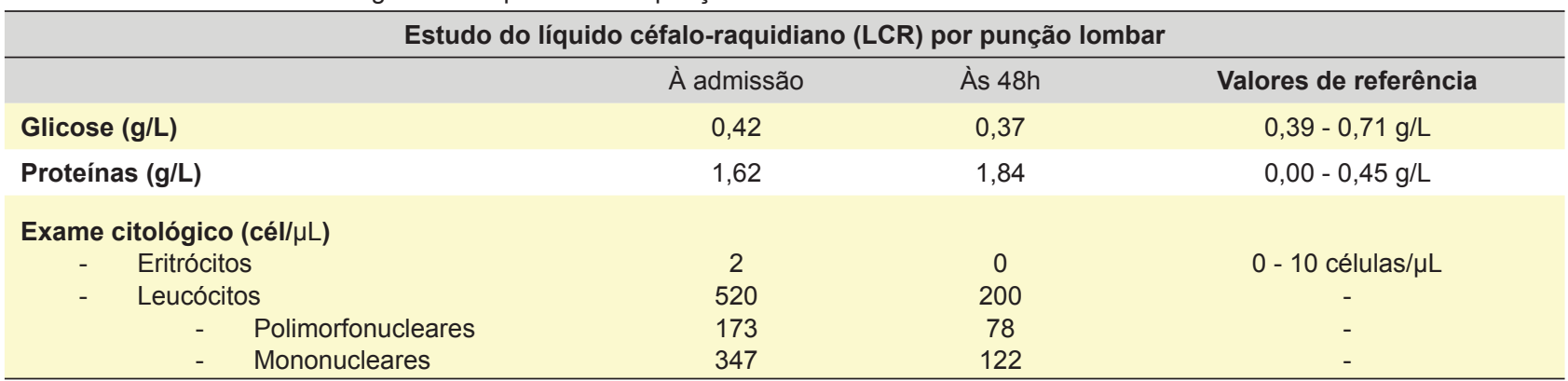

Tabela 2 - Resultados serológicos do sangue periférico e do LCR

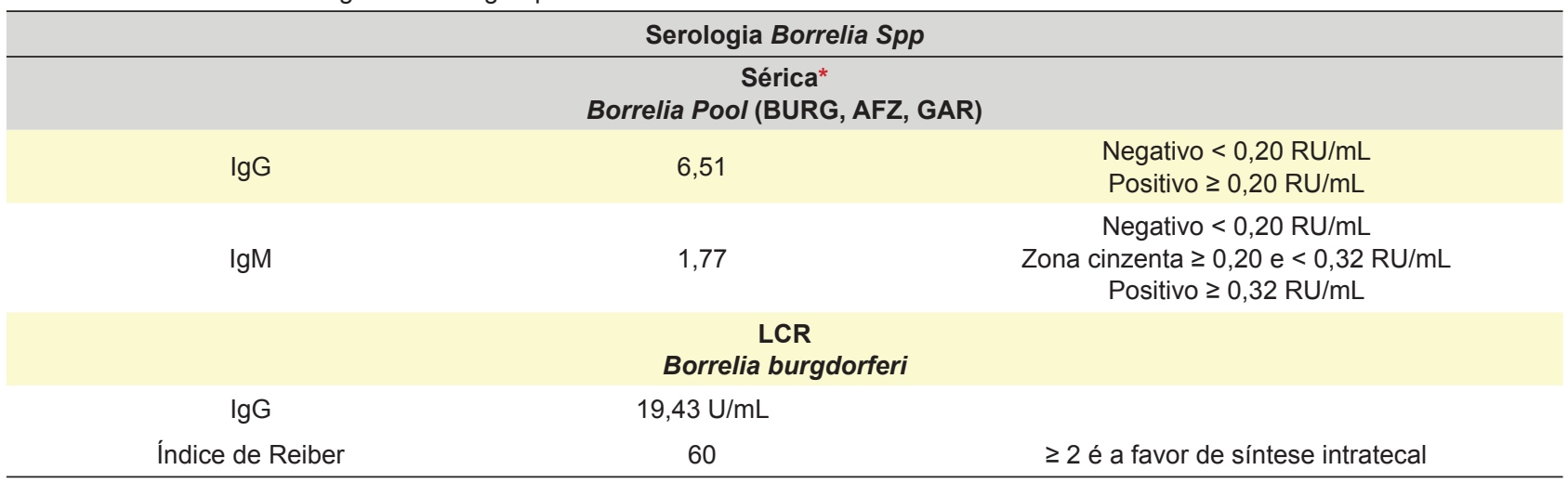

* Kit VIDAS Lyme IgG (ref. 30320 - BIOMÉRIEUX) - Sensibilidade quando IgM e IgG positivos de 91,5\% e Especificidade de IgG, para regiões de alta prevalência, de 99,7\%. Western-blot: Kit EUROLine BORRELIA IgM (ref. DN2131-3201M - EUROIMMUN).

1), mas aumento das proteínas. Não se verificou isolamento microbiológico em exame directo, cultural e pesquisa molecular de vírus (herpes simplex 1 e 2 , VZV, EBV, CMV, adenovírus, enterovírus). A serologia sérica foi positiva (IgM e IgG) para Borrelia spp, confirmada por Western-blot, positividade também objectivada no líquor, com evidência de produção intratecal (Tabela 2). Ressonância Magnética cerebral e do neuro-eixo normais. Não houve evidência de atingimento cardíaco ou osteoarticular. O estudo auto-imune não mostrou alterações (C3, C4, anti-dsDNA, anti-SS-A, anti-SS-B, ANCA, ANA inespecífico). Foram excluídas imunodeficiências (VIH 1-2 e imunoglobulinas).

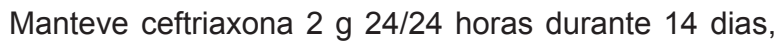
com resposta favorável ao segundo dia. À data de alta, encontrava-se assintomático. Cumpriu mais 14 dias de doxiciclina $100 \mathrm{mg}$ 12/12 horas em ambulatório, num total de 28 dias de antibioterapia. Foi reavaliado em consulta passado um mês admitindo melhoria do estado geral, sem recidiva das cefaleias, e apresentando exame neurológico normal e resolução da astenia. Retomou as actividades académicas e o exercício físico regular.

\section{DISCUSSÃO}

Consideramos que o caso clínico descrito, atendendo ao contexto epidemiológico, configura uma neuroborreliose tardia, embora sem conhecimento, ad initium, de lesões de picada de artrópode ou eritema migrans. Interpretamos: 1) inoculação na Eslovénia em junho de 2016, período sazonal onde a picada pelo vector é mais provável, 2) apresentação inaugural com episódios de cefaleias ainda na Bélgica, possivelmente num quadro de meningoencefalite aguda, não documentado e auto-limitado e 3) posterior evolução para cronicidade, sendo a astenia o sintoma inespecífico preponderante que culminou em meningoencefalite linfocítica, já em Portugal, mais de seis meses depois.

As apresentações inicial e tardia seriam facilmente interpretadas em contextos distintos, se não se tivesse levantado a suspeita epidemiológica da relação temporal com a viagem prévia. O eritema migrans não é obrigatório. Apenas $40 \%$ - $50 \%$ das pessoas identificam a picada e outros $20 \%$ - 30\% recordam a lesão cutânea. ${ }^{2,7}$ As duas semanas de intervalo encontram-se no período médio de incubação (14 dias), variando entre dois dias a três meses, por disseminação hematógenea ou nervosa (radicular). ${ }^{1,2,6}$ A apresentação inicial não foi a mais habitual em território europeu (meningorradiculite) e a resolução do quadro neurológico agudo sem tratamento dirigido terá levado a que não se prosseguisse o estudo.

Para o diagnóstico de neuroborreliose não basta a serologia sérica positiva. Documentou-se um aumento de lgM e de IgG, apontando para uma instalação não aguda. A evidência de produção intratecal de anticorpos lgG específicos contra Borrelia spp, validada pelo índice de Reiber aumentado, demonstra uma resposta humoral em curso no sistema nervoso central (SNC).

Relativamente ao tratamento é prática corrente a utilização das cefalosporinas, como a cefixima ou a ceftriaxona. Embora haja dúvidas sobre a sobrevivência residual de espiroquetas, os esquemas recomendados no atingimento crónico do SNC situam-se entre os 14 e os 28 dias. Estudos recentes não revelam aumento de morbimortalidade com a doxiciclina oral. ${ }^{8}$ Assim, pela rápida melhoria, por se 
encontrar em época académica de exames, e pelo conforto posológico, procedeu-se à mudança de antibioterapia, que completou em ambulatório.

Findo o tratamento, alguns doentes mantêm sintomas inespecíficos (fadiga, parestesias, insónia, cefaleias, mialgias ou artralgias), o que tem levado à especulação de uma síndrome de fadiga crónica ou síndrome pós-doença de Lyme. ${ }^{9,10}$ Múltiplos estudos efetuados neste grupo não apontam relevância na duração da antibioterapia no seu surgimento ou persistência. ${ }^{10,11}$ Neste caso, a resolução da astenia foi dos pontos mais salientados.

Concluindo, sendo Portugal um destino cada vez mais frequente, com residentes estrangeiros temporários, o conhecimento da epidemiologia de doenças infecciosas

\section{REFERÊNCIAS}

1. Koedel U, Fingerle V, Pfister HW. Lyme neuroborreliosis - epidemiology, diagnosis and management. Nat Rev Neurol. 2015;11:446-56.

2. Rizzoli A, Hauffe HC, Carpi G, Vourc'h GI, Neteler M, Rosà R. Lyme borreliosis in Europe. Euro Surveill. 2011;16:pii=19906.

3. Halperin JJ. Nervous system Lyme disease. Handb Clin Neurol. 2014;99:1473-83.

4. Reik L, Streere AC, Bartenhagen NH, Shope RE, Malawista SE. Neurologic abnormalities of Lyme disease. Medicine. 1979;58:281-94.

5. Mygland A, Ljøstad U, Fingerle V, Rupprecht T, Schmutzhard E, Steiner I, et al. EFNS guidelines on the diagnosis and management of European Lyme neuroborreliosis. Eur J Neurol. 2010;17:8-16.

6. Wormser GP, Dattwyler RJ, Shapiro ED, Halperin JJ, Steere AC, Klempner MS. et al. The Clinical Assessment, Treatment, and Prevention of Lyme Disease, Human Granulocytic Anaplasmosis, and Babesiosis: Clinical Practice Guidelines by the Infectious Diseases Society of America. IDSA Guidelines. CID 2006:43. típicas do viajante em espaço europeu não deve ser esquecido nos diagnósticos diferenciais em utentes que recorrem aos nossos serviços de saúde.

\section{CONFLITO DE INTERESSES}

Os autores declaram não ter nenhum conflito de interesses relativamente ao presente artigo.

\section{FONTES DE FINANCIAMENTO}

Os autores declaram não ter recebido qualquer financiamento, por fonte externa, para a realização deste artigo.

\section{CONSENTIMENTO DO DOENTE}

Obtido.

7. Logar M, Ruzić-Sabljić E, Maraspin V, Lotric-Furlan S, Cimperman J Jurca T, Strle F. Comparison of erythema migrans caused by Borrelia afzelii and Borrelia garinii. Infection. 2004;32:15-9.

8. Ljøstad U, Skogvoll E, Eikeland R, Midgard R, Skarpaas T, Berg A, Mygland $A$ et al. Oral doxycycline versus intravenous ceftriaxone for European Lyme neuroborreliosis; a multicentre, non-inferiority, doubleblind, randomised trial. Lancet Neurol. 2008;7:6905.

9. Nemeth J, Bernasconi E, Heininger U, Abbas M, Nadal D, Strahm C, et al. Update of the Swiss guidelines on post-treatment Lyme disease syndrome. Swiss Med Wkly, 2016;146:w14353.

10. Fallon BA, Keilp JG, Corbera KM, Petkova E, Britton CB, Dwyer E. et al. A randomized placebo-controlled trial of repeated IV antibiotic therapy for Lyme encephalopathy. Neurology. 2008;70:992-1003.

11. Krupp LB, Hyman LG, Grimson R, Coyle PK, Melville P, Ahnn S, et al. Study and treatment of post Lyme disease (STOP-LD): a randomized double masked clinical trial. Neurology. 2003;60:1923-30.

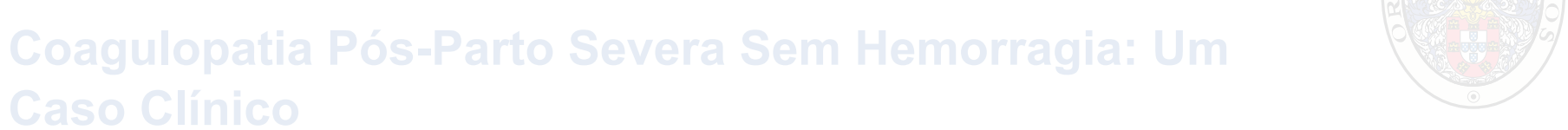

